\title{
Reflexiones psicoanalíticas sobre la vida, poesía y muerte de Sylvia Plath
}

\section{Carmen Lucía Jijón*}

\section{Resumen}

La obra de Sylvia Plath no puede desligarse de su atormentada existencia. Al estudiar su poesía se encuentran marcas textuales relacionadas con acontecimientos de su vida que revelan lo que posiblemente la condujo a suicidarse. Desde la teoría psicoanalítica de Freud, Lacan y otros teóricos, se evidencia que la palabra poética de Plath, como síntoma, devela rasgos de neurosis obsesiva. En sus obras se revelan su angustia y sufrimiento, al igual que su dominio técnico y talento, que la convirtieron en una voz innovadora de la poesía del siglo $\mathrm{XX}$, a la vez que manifiestan su dependencia de la escritura para el sostenimiento de su fragilizado psiquismo.

\section{Palabras clave}

Plath, poesía, obra, feminismo, Psicoanálisis, interpretación, neurosis obsesiva, muerte, suicidio, acting out, ritual.

\begin{abstract}
Sylvia Plath's work is inseparable from his tormented existence. When studying his poetry, textual markers related to events in his life can be found, revealing what possibly led her to suicide. From Freud, Lacan and other theorist's psychoanalytic theories, it is evident that the poetic word of Plath reveals, as a symptom, features of obsessive neurosis. His works expose his anguish and suffering, as well as his technical mastery and talent, which makes her an innovative voice in the poetry of the twentieth century, while showing its dependence on the writing for the upkeep of his weakened psyche.
\end{abstract}

\section{Key words}

Plath, poetry, work, feminism, Psychoanalysis, interpretation, obsessive neurosis, death, suicide, acting out, ritual.

Forma sugerida de citar: Jijón, Carmen Lucia. 2011. "Reflexiones psicoanalíticas sobre la vida, poesía y muerte de Sylvia Plath”. Universitas 14. Enero/Junio. Pp. 73-97.

Psicóloga clínica (Pontificia Universidad Católica del Ecuador).clgijon@yahoo.com 


\section{Introducción: vida, muerte y poesía}

Considerada un ícono, una mártir feminista y una figura de culto, Sylvia Plath y su obra difícilmente se pueden separar. Su novela The Bell Jar ha sido comparada con la del autor J.D. Sallinger, The Catcher in the Rye; como tales, reflejan los conflictos y vicisitudes de los adultos jóvenes. Ganó el premio Pulitzer de poesía, a pesar de que había muerto hacía casi veinte años, con la publicación de sus Poesías Completas, un hecho insólito, pues rara vez se concede el premio a título póstumo. Para entender a este personaje emblemático y a su obra, y encontrar algo de claridad en el porqué de su trágico final es esencial conocer y recorrer la relación entre su vida y sus escritos. También se profundizará la vinculación entre la escritura, en especial la poética, y el síntoma, que es elusivo en el sentido de develador de la verdad y también un modo de funcionamiento psíquico, desde consideraciones psicoanalíticas.

Este recorrido está enmarcado en una mirada que anuda la vida, la poesía y la muerte de Plath para comprender una obra compleja y multidimensional, que revela, a la vez que esconde a la autora. Precisamente esta diversidad es la que dificulta una interpretación, ya que su escritura innovadora e inusual, la captura de la voz narrativa junto con el tono enérgico y doloroso, las hermosas imágenes, un lenguaje preciso y una técnica impecable invitan y eluden las complejidades de la vida personal de la autora, la forma en que nunca aborda sino que esquiva los momentos claves de la misma, transformando lo personal en lo político y desestabilizando al lector en su sentido de seguridad y cordura (Wisker, 2001: 2). Por ello, desde el psicoanálisis, se ha buscado dar razón de una relación entre el retrato íntimo de esta escritora; revelado y oculto por ella misma en su obra, resaltando la intensidad de la lucha personal y literaria, del violento fin de la misma y de su inquietante y fascinante poesía. Considerando que para Sylvia Plath su escritura, y en particular sus creaciones poéticas, son a la vez su voz y su forma de relacionarse tanto con su mundo interno como con los acontecimientos del mundo externo; su vinculación con la palabra poética se considera su síntoma, enmarcado en la estructura psíquica que la contiene. 


\section{Análisis de la obra de Plath desde distintas perspectivas}

Tanto la vida como la obra de Sylvia Plath están llenas de fascinantes paradojas. Esta mujer que parecía una chica dorada de los cincuentas, académica de Fulbright en Cambridge, de la generación de la posguerra, publicando sus poemas y cuentos desde muy joven (su primer poema fue publicado en el periódico local, cuando tenía 8 años), con una técnica excepcional e imaginación desbordante, también fue considerada una escritora de los extremos, aventurándose a publicar sus poemas sobre suicidio, locura y muerte peligrosamente confesionales y subversivos; una joven autodestructiva, llena de rabia y resentimiento. Por ello, el análisis de su obra poética se lo aborda desde distintas perspectivas, cada una de ellas, penetrando en una capa más profunda que la anterior, leyendo de diferente manera los símbolos y recursos de sus complejos poemas.

En algunos de los poemas de Plath, especialmente los de su última época, se devela no solo el control y la calidad técnica de su obra, sino también un contenido que impacta al lector. Por ejemplo, en Lady Lazarus, Daddy y Edge, Plath utiliza un narrador en primera persona, lo cual genera la impresión de una experiencia personal; casi de una confesión, transmitiendo la idea de que los horrores de la historia son fundamentalmente personales. Una de las características de la poesía más tardía de Plath es la forma en que una estrofa se corta en un verso, cuyo sentido solo puede completarse en la siguiente estrofa. Esto le da al poema un fuerte acento con un controlado ritmo e imágenes que fluyen al ser leídas en voz alta, pero no al ser vistas en el papel.

Lady Lazarus ${ }^{1}$

He vuelto a hacerlo Un año de cada diez

Lo consigo: devenir

En esta suerte de milagro andante, volver mi piel

1 Aquí están transcritos los dos primeros versos de este poema, del libro Poesía Completa traducido por Xoán Abeleira. 
Brillante como la pantalla de una lámpara nazi,

Mi pie derecho,

En 1962, Sylvia Plath expresó en cuanto a su obra, que la consideraba una conexión con el mundo a través del filtro de la voz narrativa, diciendo que si bien sus poemas salen inmediatamente de sus experiencias sensuales y emocionales; creía que en la escritura debía ser capaz de manipular las experiencias, transmutándolas en arte y no solamente como un registro de las mismas. Estas vivencias a menudo difíciles de reconocer directamente debido a sus conflictivos contenidos emocionales son expresadas de manera creativa y reflexiva en su poesía, como respuestas al mundo que la rodea. Por momentos lo hace de manera estilizada y siniestra, debido, principalmente, al manejo de los ritmos y sonidos y de los patrones y repeticiones que canalizan magistralmente los estados emocionales, las atmósferas de los poemas y la voz narrativa de los mismos, como en su famoso poema Daddy.

Una locomotora, una locomotora Silbando, llevándome lejos, como a una judía. Una judía camino de Dachau, Auschwitz, Belsen.

Empecé a hablar como una judía. Incluso creo que podría ser judía.

Antes del 'despertar feminista' de los Estados Unidos y, por lo tanto, de las voces poéticas femeninas ${ }^{2}$ alrededor de este tema, Plath escribió sobre las mujeres, su cuerpo, sus roles en la sociedad y las expectativas impuestas por la cultura versus el desarrollo del individuo, en poemas como Spinster y The Applicant. Un tema poco tratado antes de Plath por otras poetas es la sexualidad femenina, a veces agresiva, a veces víctima o pasiva. Plath exploró tempranamente las relaciones y la búsqueda de la identidad particulares a las mujeres, en una diversidad de roles que generaban confusión entre la supuesta libertad y las restricciones sociales de su época.

2 El mayor ejemplo es la poeta Adrienne Rich, cuyos escritos feministas se enmarcan en la década del setenta. 
El feminismo es una de las corrientes críticas que más ha valorizado la voz de Plath. Ciertas críticas apuntan a que las imágenes que expondría Plath en su poesía tienen que ver con la idea de victimización y martirio dentro de una posición social de subordinación femenina en un mundo patriarcal, lo que reduciría mucho la exploración de la poeta con respecto a los extremos y las limitadas opciones que las mujeres tenían tanto en Estados Unidos como en Inglaterra, después de la Segunda Guerra Mundial. Las críticas feministas tienden a concentrarse en la representación de las mujeres en los escritos, estableciendo lo que se conoce como l'écriture féminine. Esta noción tiene la creencia de que hay una clase particular de escritura específica de las mujeres en términos de expresión, imágenes, tonos y temas, en especial la escritura 'desde el cuerpo'.

Algunos poemas de Plath exploran el lado creativo, amoroso, imaginativo de las mujeres, al igual que las contradicciones de la vida diaria. Otros exploran experiencias dolorosas, como el aborto, o sentimientos tales como la ira, el deseo de venganza, la locura, la traición y otros que no fueron tratados antes en la poesía escrita por mujeres de una manera tan frontal y vehemente. Plath también exploró los diferentes roles que estaban disponibles para las mujeres, al igual que las oportunidades, su propia identidad y posibilidades como mujer y escritora (Wisker, 2001: 37). En ese sentido, Plath se adentró en formas de experimentar las vidas de las mujeres, al mismo tiempo que creó personajes que representan los distintos estereotipos femeninos; entre ellos: la bruja, la mujer fecunda, la mujer estéril, la seductora, la otra mujer -en su poema The Other-, cuando enfrentaba la infidelidad de su esposo. También aborda temas como: la solterona en su poema Spinster; la mujer que atrae sexualmente el interés y después la violencia de todos los hombres en Strumpet Song; la madre tierra, fértil y llena de hijos que pierde otras formas de creatividad entrando en la locura en Two Sisters of Persephone; o su opuesto, el vacío de la esterilidad en Childless Woman. De esta manera Plath se debatió en las distintas opciones, siempre constreñidas, de la experiencia femenina y los extremos de la misma a los que estaban abocadas las mujeres en los años cuarenta hasta 1960.

Two Sisters of Persephone Hay dos jóvenes: una sentada Dentro de la casa; la otra, fuera. 
Un dueto de luz y de sombra Interpretado todo el día entre ellas.

Sylvia Plath siempre se consideró a sí misma como un ser político y creía que era obligación de los artistas involucrarse y denunciar los sucesos políticos que marcaran su tiempo. Ella no se pudo considerar simplemente como una poeta intensamente personal, sino también como un ser consciente de la conectividad histórica ${ }^{3}$ entre el sujeto y su entorno. Su obra es una denuncia de los constructos sociales y explora las intersecciones ideológicas detrás del arte y la sociedad, en especial sus contradicciones. Las experiencias culturales de las mujeres durante la posguerra son un tema fundamental en su poesía; en especial la crítica que hace a la construcción de modelos y argumentos en cuanto a los roles de género. En su poesía y su novela también trabajó la identificación con el holocausto y con un momento brutal en la historia de los Estados Unidos, como la muerte de los Rosenberg por crímenes políticos. Además están presentes temas que le preocupaban profundamente como el desprendimiento nuclear y la lluvia ácida, la militarización, los campos de concentración y los juicios de criminales de guerra nazis. La identificación con dichos momentos históricos podía ser muy personal, por ejemplo en los poemas Lady Lazarus o Daddy, donde se identifica con una víctima judía frente al nazismo y al holocausto:

Lady Lazarus

Esta suerte de milagro andante, volver mi piel Brillante como la pantalla de una lámpara nazi, Mi pie derecho,

Un pisapapeles, Mi rostro, una fina tela de lino, Judía, sin rasgos.

3 Es la relación entre cosas o eventos, tanto de causa y efecto como si ambas comparten características similares. En matemáticas significa que ninguno de los componentes de esta relación tiene valor por sí mismo, sino solamente en la unidad. 
Ah, arráncame este paño y Despelléjame, enemigo mío. ¿Qué es lo que tanto te aterroriza?

\section{Desde la perspectiva de M.D. Uroff ${ }^{4}$}

De acuerdo con Uroff, es a través de la hipérbole, la parodia y la caricatura que Plath articula tanto el control de sentimientos de horror como la locura; la enfermedad o las relaciones restrictivas, y pone como ejemplo los poemas Miss Drake Proceeds to Supper, Zoo Keeper's Wife, Tulips, The Tour y The Applicant. Uroff plantea que el sujeto literario del que hace uso Plath en su obra manipula dramáticamente su discurso para controlar las experiencias personales en la obra poética. También propone que en los poemas antes mencionados, al igual que en los más tardíos como Lady Lazarus o Daddy, Plath no se ocupa tanto de la naturaleza de la experiencia en sí misma, sino que está comprometida con la manera en que la mente trata circunstancias extremas o experiencias hacia las cuales el sujeto del poema es excesivamente sensible.

La forma en que las voces narrativas tienden a realzar o exagerar las experiencias ordinarias sirve para intensificar las habilidades manipulativas de la mente, como un vehículo para la expresión de aquello que el terror no permite manifestar. De acuerdo con Uroff, estos sentimientos o pensamientos dan lugar a una rigidez mental, por lo que utiliza la caricatura y la parodia como una manera de dar cabida a aquello que es inexpresable. De esta manera, la poeta controla, por medio de sus personajes, el horror que le produce el conocimiento de sí misma. Las voces narrativas dan cuenta de cómo mantiene a raya, mediante dichos rituales, los sentimientos que le son inmanejables y le producen o produjeron horror, como el miedo a la pérdida y al abandono en el caso de Plath. En el poema Little Fugue, la voz que narra es la de una mujer que se debate entre el terror a las amenazas, procurando, a través de rituales diarios como atender a

\footnotetext{
4 Margaret Dixie Uroff, reconocida crítica literaria cuyo trabajo más importante se centra en Plath y Hughes. Me he basado en su ensayo: Sylvia Plath and Confessional Poetry: A Reconsideration, que se puede encontrar en la Web en: http://www.sylviaplath.de/plath/uroff.html
} 
su bebé, o incluso reconocer su cuerpo, mantener algún sentido de normalidad, intentando sobrevivir (Wagner Martin, 1997: 235). En el poema The Tour, lo que se evidencia por medio de la siniestra e irónica voz narrativa es la forma en que una mente creativa puede exaltar la auto-laceración. La manipulación de las imágenes debido al uso frecuente de metáforas y de símiles -sobre las cuales Plath basaba su poesía (Blake, sitio web)- y del sufrimiento es una subversión de los poderes creativos de la poeta y se transforma en una estrategia de resistir en lugar de explorar su situación (Uroff, 2009).

Uroff señala que en el poema Lady Lazarus la voz narrativa es capaz de admitir la desesperación que subyace bajo el tono triunfante y desafiante que mantiene a lo largo del poema, a diferencia de los poemas anteriores; por ejemplo en los versos: Qué desperdicio/ aniquilarse cada década. Sin embargo no se despoja de ese autocontrol rígido, es más, lo acentúa por medio de un rango que va desde alegría frenética hasta amenazas maliciosas. Este poema también evidencia las formas en que piensa la mente de una persona al borde del suicidio. No obstante, más que una reflexión sobre esos pensamientos y experiencias, Plath hace una exposición de los mismos. La intención de este poema, mórbido y sarcástico, al igual que otros de la misma época, era que fueran leídos en voz alta, por lo cual utiliza un lenguaje más coloquial, como lo hizo también en Daddy. En Lady Lazarus la narradora es muy clara al exponer lo que le sucede o cómo es percibida por otros, pero no revela sus propios apremios o sentimientos frente a ese 'arte' que pretende dominar: el de la muerte. La fascinación de la poeta con las imágenes paródicas da cuenta del fracaso de los sujetos narrativos al tratar de elaborar sus experiencias.

Persisten las imágenes crueles y las alusiones a los campos de concentración nazis como una burla de sí misma y de la forma en que parece ser percibida por ese personaje del poema, que es ella misma, el tirano. También utiliza el recurso de la repetición como medio para enfatizar y, conjuntamente, alivianar las imágenes. Al estar escrito en estrofas de tres versos, el poema goza de un ritmo controlado y cortante, pero a la vez musical. Si bien el poema trata sobre Lady Lazarus, la mujer que intenta suicidarse repetitivamente, también es una crítica ante la sociedad que con admiración enfermiza se regocija en un suceso de tal naturaleza. Plath enfrentaba también a esa sociedad crítica en el personaje del doctor que aparece en el poema. Más que un manifiesto suicida, este poema 
es un testimonio más del disgusto que sentía ante aquellos que se presentaban como un morboso público frente al dolor, y una interpelación a ese público.

Concluye Uroff que los variados personajes de los poemas de Plath, desde los más tempranos a los últimos que escribió, no confiesan nada, sino que erigen barricadas contra la autorevelación por medio de rituales absorbentes. Por ejemplo, en el poema Miss Drake Proceeds to Supper, el personaje tiene rituales para alejar la malicia, mas no confiesa su angustia ni lo que producen en ella esas imágenes. Mediante el análisis del estilo poético de Sylvia Plath podemos ver evidencias de una estructura neurótico-obsesiva; no solamente en el contenido mismo del poema, sino en la forma en que se utilizan las figuras poéticas y presentan la voz narrativa. Una estructura llena de defensas y barricadas que pretenden aislar la angustia y el malestar y hasta la propia oscuridad del sujeto a través de la evitación compulsiva y ritualística.

Miss Drake Proceeds to Supper

Como ya es ducha En esos elaborados rituales

Que atenúan la malicia

De la mesa nudosa y la silla curva, La recién llegada

Viste de púrpura, anda con cuidado

Entre sus secretas combinaciones de cáscaras de huevo

Y frágiles colibríes, Camina de puntillas, pálida como un ratón, Entre las rosas damascenas Que, poco a poco, van abriendo sus cien pétalos velludos Para devorarla y arrastrarla al interior Del diseño de la alfombra. 


\section{Poesía y síntoma}

A partir de los distintos análisis sobre la poesía de Sylvia Plath surgen interrogantes con respecto a la estructura de la autora. Estructura entendida desde el psicoanálisis, que pueda explicar esta intrincada simbiosis entre la vida: intensa, paradójica y compleja de Plath y, su igualmente enérgica, a veces violenta y extrema poesía, como un tejido que se elabora en la medida en que su obra se construye y se revela, a la vez, que se oculta gracias al gran dominio técnico y a su talento.

Desde una mirada psicoanalítica se puede preguntar ¿Es la poesía un síntoma? "Lo es en cuanto emergente. Un trabajo de construcción libre y velado a la lógica, inasible como un sueño, con altas dosis de ambigüedad y emoción y cierto sentido que permanece"s. Es así como la palabra, y la palabra poética en particular, al igual que un síntoma, toma cuerpo y se materializa en un cuerpo otro hecho de tinta y papel. En este sentido, no se ha liberado ni se ha resuelto el conflicto interno, sino que se ha tornado visible y explícito en lo escrito. Suponiendo que el poema tiene una función y ésta sea la de representar, la de traer al ser una disposición y una palabra individuales; la articulación entre la escritura poética y el síntoma depende en la medida en que el poeta no pueda desligarse de la escritura. El poema es más que una creación, es una forma de funcionar en el mundo y es una formación de compromiso, en tanto las defensas se expresan igualmente en él. Por lo tanto, la poesía como síntoma: “... es un lenguaje cuya palabra ha de ser liberada" (Anzieu et al., 1981: 18); palabra que se libera en la poesía, como en ninguna otra escritura, por las licencias poéticas. La poesía es lo que le permite a la poeta vivir. Plath misma lo dice de su impulso a escribir, que es una voz en su interior que no permanece tranquila ${ }^{6}$, la voz que la impulsa a buscar un asidero en el cuerpo del poema, reflejando sus propias angustias y fantasías en el texto, y su estructura neurótico-obsesiva en el estilo literario.

5 Post de Javier Galarza, De la poesía como síntoma y el lugar vacante de Dios, en su blog, http:// javiergalarzants.blogspot.com

6 De un escrito de 1948 en los diarios de Sylvia Plath "You ask me why I spend my life writing?...I write only because/there is a voice within me/that will not be still". 
La hipótesis del psicoanalista Bernard Cadoux, con respecto a la escritura, es que ésta vendría a suplir un fallo del aparato psíquico; un fallo considerado como un desfallecimiento del mismo, dando lugar a ciertos elementos traumáticos que el sujeto no puede elaborar en sí mismo. La escritura entonces proveería una inscripción externa a aquello que no se ha inscrito en el interior o no puede inscribirse en él. Ella aseguraría una suerte de trabajo de contención y de elaboración que el psiquismo no ha podido efectuar. La escritura sería el último bastión del Yo (moi) contra el derrumbamiento que le amenaza. El psicoanalista Didier Anzieu propone que el estilo es lo que permite que el carácter del autor y su imagen del cuerpo depositen su rasgo en el texto. Al mismo tiempo la escritura constituye una función psíquica, en el sentido en que entran en juego las fantasías, la libertad de la palabra en la poesía, que se convierte en un medio de salvataje psíquico (Cadoux, 1999: 38). A la vez que el sujeto puede asignar un lugar dentro del psiquismo a elementos inasimilables, también puede ensayar una nueva realidad, una especie de bosquejo para su vida. Vemos ambos casos en la poesía de Sylvia Plath: por un lado fantasía con realidades opuestas, como los distintos roles de género que explora, también con enfrentamientos personales y sociales; especialmente con ese padre ausente al que reclama a pesar de su arrolladora presencia -el poema Daddy y los poemas sobre abejas son los más reveladores en ese sentido- $\mathrm{y}$, por otro lado, su búsqueda de la perfección y la constante lucha con la obsesiva idea de la muerte.

Plath escribió en sus diarios: "El no ser perfecta me hiere", afirmación que, más que un autorreproche, es una aseveración de búsqueda inefable de un Superyó demasiado exigente, hasta el punto de la crueldad. Freud descubrió que crueldad y severidad contra sí mismo con sentimiento de culpa son tanto más implacables cuanto que el sujeto es más virtuoso. Se puede entender entonces que una mujer con un talento tan notable, que destacaba en todo ámbito, incluso por su excesiva pulcritud y su deseo de hacerlo todo a la perfección, tanto su profesión como cualquier otro emprendimiento, haya demostrado hacia sí misma excesiva severidad, sin ser capaz de alcanzar los estándares de excelencia que se había autoimpuesto.

Cecilia Bustamante (Bustamante, sitio web) escribe sobre Sylvia Plath : 
George Steiner, quien fue también su amigo, dice que, pese a su sonrisa de covergirl, este ser era «fieramente autonegador, autocontrolador, ansioso, reticente [...] logró una poesía de deslumbrante finura y control que solo una necesidad irresistible pudo haberlos ocasionado». Robert Lowell acierta sutilmente al hablarnos de su «controlada alucinación» $\mathrm{y}$ de que su poesía es «la autobiografía de la fiebre». Que «la inmortalidad de su arte (tuvo como precio) la desintegración de la vida».

Adjetivos como: autonegador, autocontrolador y reticente son algunos de los rasgos de la neurosis obsesiva, al igual que la pulcritud y la búsqueda de la perfección. Esta lectura entre el síntoma obsesivo de Plath y su estilo poético, es solo una mirada hacia la unión de vida y obra de una autora emblemática, controversial y talentosa, que hoy, tal vez más que antes, ha sido elevada a figura de culto y representante de los extremos que desgarran no solo a los poetas sino a una sociedad de obturaciones.

\section{Sobre la neurosis obsesiva}

Para entender un poco más a la 'neurosis obsesiva', y el porqué de este anudamiento con la vida y obra de Plath, es importante razonar algunas características de la misma y el desarrollo que ha tenido este concepto. De esta manera, se concebirá mejor la relación entre la neurosis obsesiva y la muerte, y bajo esta luz se podrá comprender y mirar la vida y obra de Plath y su fatídico final, tan opuesto a la defenestración melancólica o la supuesta locura, en el sentido de psicosis, que ha perseguido a la figura de Plath en los medios académicos.

\subsection{Neurosis obsesiva como Zwangsneurose}

Freud plantea una innovación nosográfica al hablar de la Zwangsneurose, obsesión o neurosis de compulsión, a partir de síntomas, de pensamientos o de actos compulsivos. Construyó esta nueva neurosis por analogía con el mecanismo de la histeria según sus dos tiempos. Un primer tiempo de orden etiológico: hubo en la infancia una excitación sexual precoz. Si el trauma es sufrido pasivamente en la histeria, por el contrario, hubo actividad con placer en la neurosis 
obsesiva. Un segundo tiempo: los efectos que se derivan del mismo, porque son inconciliables con el Yo, se desatan de sus representaciones primarias para operar una fausse liaison ('falsa unión') con nuevas representaciones por desplazamiento. Esta sustitución es una defensa del Yo. No hay una represión sin retorno de lo reprimido, no por una conversión somática como en la histeria, sino por una transposición sobre otras representaciones más conciliables con el Yo. Estas son las obsesiones propiamente dichas como formaciones de compromiso: autorreproches, inhibiciones para actuar, aislamiento de una representación, anulación de eventos del pasado, rituales privados.

En Tres ensayos sobre la teoría sexual de 1905, Freud marca un cambio, mostrando la importancia capital de las zonas erógenas y de las pulsiones parciales, poniendo en juego un Lustgewinn (o 'plus de goce' como lo traduciría Lacan). Las defensas del Yo operan un retorno regresivo a un estadio anal. En el artículo de 1908, Carácter y erotismo anal, Freud hace la unión entre el objeto anal y la neurosis obsesiva con los síntomas de preocuparse del orden o de la limpieza y con sus obstinaciones. Es dentro de esta perspectiva que, en 1909, inicia el análisis de El hombre de las ratas. La revelación a éste de un "horror por un goce por él mismo ignorado" adviene durante el famoso relato por el capitán X de un suplicio oriental de orden anal. Es contra esta representación que surgen mandatos y juramentos: "tú debes...". En 1913, en el artículo La disposición a la neurosis obsesiva, Freud hace un vínculo entre neurosis y las pulsiones erótico-anales y sádicas. Las pulsiones parciales son concentradas sobre la elección de objeto, mientras que la primacía de las zonas genitales no se ha establecido aún. Este último periodo, desde 1913 a 1923, es al mismo tiempo el más audaz y el más problemático. Freud aplicó el "tú debes" de $E l$ hombre de las ratas a toda neurosis obsesiva: hay una relación intrínseca entre éste y la función de Superyó de acuerdo a la segunda tópica. En Ensayos de psicoanálisis dice: "aquello que reina dentro del Superyó es una pura cultura de la pulsión de la muerte. El Superyó puede devenir hípermoral y, por tanto, tan cruel que solo el ello puede ser".

En 1923, en El Yo y el Ello, Freud dice que el declive del complejo de Edipo viene de una interiorización de la prohibición paterna. En tanto que conciencia moral es la dominación del Superyó sobre el Yo. La prohibición paterna a la que se refiere es la de la madre, es la prohibición del incesto. Aquello que concernía 
al sadismo de lo erótico anal es aplicado al Superyó. En Inhibición, síntoma $y$ angustia, Freud admite su perplejidad a propósito de la neurosis obsesiva, donde se observa un doble fenómeno: uno de desmesura y el otro de inversión. En un principio hay una desmesura. Después de la declinación del complejo de Edipo hay la creación o consolidación del Superyó. Ahora bien, dentro de la neurosis obsesiva, estos procesos sobrepasan la medida normal; a la destrucción del complejo de Edipo se añade la degradación regresiva de la libido; el Superyó deviene especialmente severo y duro, mientras que el Yo desarrolla a partir del mandamiento del Superyó formaciones reactivas importantes que toman la forma de escrúpulos, de la piedad o de la limpieza.

\subsection{Los aportes de Lacan respecto a la neurosis obsesiva}

Según Freud, el acceso al deseo supone la castración concerniente a la posición primaria del hijo o de la hija de ser por su imagen el falo de la madre, en tanto que éste le falta. En un primer tiempo el bebé ocupa el lugar del falo de la madre. Esta es la posición primordial a partir de la que, en un segundo tiempo, la castración podrá cumplirse, al decir del psicoanalista Philippe Julien en su decálogo del neurótico obsesivo: “¡Tú no eres el falo de aquella que te ha concebido!" (Julien, 2000: 135). La neurosis no procede de una frustración de no tener el falo, sino de una castración no admitida, no subjetivada, no reconocida en su enunciado en términos de ser. El Edipo de Freud y su actualidad se resumen así: Sobre el hecho de no ser el falo del Otro, el sujeto puede aceptar el hecho de tenerlo -lado masculino- con el riesgo del peligro y la creencia de que lo podría perder; o el hecho de no tenerlo-del lado femenino-como falta y ausencia. El problema del neurótico es el de su agresividad culpabilizante con respecto a su semblante supuesto tener el falo. La confusión entre frustración del objeto real y la castración del objeto imaginario recubre aquella entre el ser y el tener. La neurosis obsesiva no viene de una frustración de la demanda de tener, sino de una castración no realizada, en cuanto a ser aquello que le falta al deseo del Otro. Esta no distinción entre demanda y deseo es una psicologización del psicoanálisis, como si la demanda fuera la expresión del deseo. En cuyo caso esta confusión es exactamente el síntoma del obsesivo. En efecto, ella determina para éste el Superyó como "figura obscena y feroz" dirigiéndose 
al sujeto por la voz insistente de la consciencia moral. Ese tú, dice Lacan, quiere todo, entiende todo, anota todo (Julien, 2000: 136).

\subsection{La neurosis obsesiva y la muerte}

En la neurosis obsesiva, según la perspectiva del psicoanalista Karl Abraham, el desarrollo de la libido discurre de manera que las tendencias de amor y odio coexisten. El obsesivo entonces, tiende a adoptar una actitud hostil hacia el mundo externo, y la libido no puede investirse en un objeto. El origen de estas actitudes hostiles se produce en la etapa anal sádica. Esta es una etapa pulsional en la cual el niño va a experimentar su dominio muscular respecto a la expulsión de las heces, sintiendo una satisfacción o insatisfacción que pueda apreciar y valorar. Es la primera expresión subjetiva del niño. El control de esfinteres es su primera experiencia de poder: poder de dar o retener sus excrementos. Al inicio de la etapa anal, en la relación entre la evacuación anal y la destrucción del objeto anal (los excrementos) prevalecen tendencias hostiles, deseos de destruir o eliminar el objeto o el mundo externo. Es la etapa más primitiva de la relación del sujeto con el objeto, donde no hay amor para el objeto, sino deseo de destrucción del mismo debido a la necesidad de expulsarlo. Posteriormente el proceso se invierte, y se da una tendencia de satisfacción que se produce por la retención de los excrementos; el niño es ya capaz de retener las heces a voluntad. En estas dos etapas de la relación anal con el objeto, el niño -dice Abraham- trata al objeto de su deseo como si le perteneciera, al igual que el contenido de su cuerpo, las heces. Según el autor, los síntomas neuróticos dan cuenta de una fijación libidinal que se manifiesta por un proceso de regresión de la libido.

En el caso de los obsesivos, ya que la regresión de la libido se produce hacia la segunda etapa de la fase anal sádica, la relación con el objeto se produce con la convivencia tanto de tendencias hostiles como amorosas, pero en términos de dominación, de tal manera que pretende tener poder sobre su objeto. Esta relación del obsesivo con su objeto se traslada invertida a las relaciones con el mundo externo, manifestando tendencias hacia la limpieza, orden excesivo y fenómenos de compulsión, como formaciones reactivas y sublimaciones frente a pulsiones sádicas. Es una manera de ejercer poder sobre las cosas, manifes- 
tando un sistema rígido, que a la vez le sirve de solución de compromiso aceptable entre él y su entorno, de modo que en el decir del neurótico existe orden aparente y organización.

El deseo enrumba los significantes que representan al sujeto que habla, lo traduce en actos y de allí nuevamente en palabras. El obsesivo se encarniza en la protección de su deseo (imposible de alcanzar). El Superyó del sujeto obsesivo fundamenta la moral a la vez que le ordena gozar. Así, la moral ligada al goce produce en el obsesivo el surgimiento de una extrema preocupación por la muerte. Este es el deseo de muerte del padre quien prohíbe y limita, lo que no da cabida a la realización del deseo, y explica el posicionamiento frente al deseo como imposible. Asimismo el sujeto obsesivo se refugia en pensamientos de religiosidad que pueden traducirse en sacrificios, renuncias altruistas o actos oblativos, que finalmente den cuenta de la renuncia aparente a su propio deseo para dar cabida a una sumisión al deseo del Otro, quien representa la autoridad. La renuncia al goce tiene como fin preservar el deseo del obsesivo, escondido a la mirada del Otro y de los otros.

Según Lacan el acto de un sujeto suicida es el único acto no fallido. El sujeto suicida puede sentirse amenazado por instancias internas a las cuales necesita dar forma. Sin embargo, dichas instancias pueden no lograr ser puestas en palabras debido a un vacío en la cadena significante. Este vacío se produce en la represión. Al retornar lo reprimido y en el intento de restituir y organizarlo, es posible que el sujeto busque una forma de metaforización en los actos. Esos actos pueden ser acting out o pasajes al acto. Se entiende acting out como un término que, al ser traducido al español, es una forma conjugada del verbo actuar. Es una conducta sostenida por un sujeto y que se da a descifrar al otro a quien se dirige. Es una demanda de simbolización exigida en una transferencia salvaje. Quien actúa en un acting out no habla 'racionalmente'. No sabe qué está mostrando, del mismo modo en que no puede reconocer el sentido de lo que devela (Chemama, 2002: 5). El acting out es una señal del retorno de lo reprimido que no puede ser puesto en palabras, el impulso inconsciente del sujeto con el fin de dar sentido que estructure y transforme aquello que no puede decirse. A través de este hecho, el sujeto ha intentado metaforizar y comunicar aquello que le perturba. 


\subsection{Los diez mandamientos de la neurosis obsesiva}

Con respecto a la neurosis obsesiva, Phillipe Julien (2000: 136-137) plantea 10 mandamientos para el obseso, que resumirían el síntoma obsesivo, entendido como el fenómeno subjetivo que constituye la expresión de su conflicto inconsciente (Chemama, 2002: 413-414). Mediante éstos, se analiza la relación de Plath con su obra, su palabra poética como síntoma y su posicionamiento dentro de la estructura obsesiva. Expuestos a continuación, la relación entre éstos y la vida, obra y suicidio de Plath se explicarán en el punto 4.

1. No demandes nada. Que tu demanda muera para realizar así tu demanda que es ser un sujeto muerto, desvanecido, borrado. Esto es lo que debes exponer.

2. Tu deseo es en verdad despreciar, anular, destruir el deseo del Otro. En efecto, es el tuyo o el suyo. Por eso hablas así: "Esto que pienso, no lo es tanto, porque es culpable, es difícil de sostener y de hacerlo progresar, porque falta que aquello que yo piense me sea propio y nunca del vecino, de otro".

3. Espera ser demandado. Espera que el Otro comprenda tu silencio. De hecho, para hacer frente a la angustia del deseo del Otro, tú la debes recubrir con su demanda: una demanda anal de dar. A cambio, sé 'una ofrenda'; no harás jamás lo suficiente para que el Otro se mantenga dentro de la existencia. Lacan decía "que no habrá nunca más grandes sacrificados que los verdaderos, los grandes obsesivos (Julien, 2000)".

4. No botes nada, acumula hasta el encumbramiento. Nunca se sabe, esto nos podría servir algún día. Amar es tener siempre algo que dar. Y para tener aquello, retén eso que tienes, ¡aprieta las nalgas! ¡Aprieta los dientes!

5. Tu propio deseo, lo invitarás mañana, pasado mañana, más tarde. Tienes tiempo: hazte el muerto. Así sabrás hacer esperar al Otro mucho tiempo, porque éste no tiene deseo sino en lo imposible. 
6. Mientras tanto, prueba algo. Supera la inhibición con proezas, la prestancia, la fanfarronería, la vanidad, como la imagen de la rana que deseaba ser tan grande como el toro. Sí, pero tú, ¡tú no reventarás jamás!

7. No hagas nada definitivo o exclusivo: ¡ningún pie dentro sin otro pie fuera! ¡Ningún avance sin la seguridad de una retirada! 'A la vez' y 'al mismo tiempo' son las palabras que deben atravesar tu palabra.

8. Frente al imperativo del Superyó que te ordena: 'igoza!', haz de tu impotencia de realizarlo una demanda dirigida hacia un maestro supuesto saber, tanto si la relación entre goce y dominio (maestría) es del orden de lo imposible o no.

9. Sométete a la orden de hierro de hacer esto o aquello. Debes sobrecargarte con un programa sin falla, sin vacío, sin respiro, para evitar la pregunta sobre el deseo del Otro.

10. Detén tu análisis el día en el que podrás aligerar tu culpabilidad, culpabilizando al prójimo. A su vez, que tu propia voz transmita esta orden de acero en torno tuyo, sin explicación ni murmullo: ¡es como es porque es como es! ¡Fin del análisis!

\section{La vida y la obra de Sylvia Plath: expresiones de una neurosis obsesiva}

El neurótico obsesivo guarda su deseo para sí mismo con mucho celo, de tal manera que no lo deja ver. Para el obsesivo, el ritual es una forma de controlar el ambiente a la vez que erige barricadas en torno a su deseo, protegiéndose de esta manera frente a los otros. No permite que nadie se acerque a su más íntimo ser. A la vez elude la responsabilidad con respecto a su deseo, dejando que la pulsión de Muerte le lleve a la inmovilidad. Así su vida se ve mortificada por rituales, hábitos y reglas. Esto es lo que M.D. Uroff plantea en su análisis de la poesía de Plath con respecto a la construcción de rituales absorbentes que 
erigen barricadas frente a la autorevelación y que se manifiesta más claramente en su poema Miss Drake Proceeds to Supper.

En cuanto al deseo del obsesivo con respeto a despreciar y anular el deseo del Otro, vemos en Sylvia Plath una negación hacia algo que venga de otros, y también que el Otro no tenga asidero o influencia sobre ella. Por eso busca en su poesía, en su escritura, algo que no se hubiera hecho antes. Durante sus años escolares y universitarios se mostró sumamente competitiva, no le gustaba compartir el reconocimiento y los premios con nadie, los deseaba para ella sola. Por lo tanto, su palabra, su voz como escritora, a la par que su búsqueda, perseguían anular a los otros en su propio ensalzamiento. Para Plath, lo más importante era la escritura como la única manera de ser libre. Dice en su diario de 1958: “...si, Si yo pudiera abrirme hacia una prosa significativa, que expresara mis sentimientos, yo podría ser libre. Libre para tener una vida maravillosa. Me siento desesperada cuando estoy verbalmente reprimida". Por ello su trabajo se dirigió a producir una voz poética única, aunque al poco tiempo de haber surgido con fuerza, Plath se suicida. ¿Es posible que en esa búsqueda por destruir el deseo del Otro, en la superación al Padre, se haya destruido a ella misma cortando toda posibilidad de vínculo con los otros?

En cuanto a la búsqueda por superar la inhibición con proezas, a la vez que es una forma de esperar ser comprendida; Sylvia Plath no escribía ni manifestaba la profunda angustia que le embargaba, o la soledad, o la tristeza, excepto en sus diarios y en sus últimos poemas. Plath esperaba ser entendida en su silencio. Ocultaba su cansancio y frustración frente a la vida ante su madre y hermano, sus amigos e incluso su propio esposo, escribiendo cartas alegres, mostrándose siempre dinámica y activa, aun en casa, cuando estaba enferma y fatigada. Por el contrario, se sentía obligada a dar y a producir: niños, comida, poemas, cartas, como en el cuarto mandamiento del decálogo del obsesivo, según Julien. De esta manera también se ofrendaba a los otros, siendo para ella lo más importante ser considerada 'buena'. A menudo manifiesta en sus poemas sentirse una ofrenda sacrificial; por ejemplo en Mary's song, apología de la imagen de Jesucristo como el hijo que ha de ser sacrificado por el bien de la humanidad, poema en el que el corazón de la narradora es como ese cordero sacrificial: 
Pájaros grises obsesionan mi corazón, Ceniza de boca, ceniza de ojo. Se asientan. En el alto

Precipicio

Que arrojó a un hombre al espacio Los hornos resplandecían como cielos, incandescentes.

Este holocausto

En el que me adentro es un corazón, Ah, niño dorado que el mundo matará para comérselo.

Debido a la preocupación que le provocaba la búsqueda incesante de la perfección, el reconocimiento de los otros con respecto a su valía y la sensación angustiosa que se derivaba de ambas, se presionaba a sí misma a mantener relaciones sexuales sin afecto, lo cual a su vez le llenaba de ansiedad. Para calmarse a sí misma, se burlaba de todos sus amantes, exhibiéndose como seductora, agresiva e infalible, simulando amarlos y, a la vez, llamándolos 'gusanos'. Establecía relaciones de terrible violencia, en las cuales ella era tanto la víctima como la victimaria. A través de estas actitudes, cumplía con el sexto mandamiento del decálogo de Julien, actuando con fanfarronería y vanidad. Asimismo vivía en la desmesura, negándose a vivir su propio deseo, ocultándolo en una búsqueda de lo imposible: la perfección o, como dijo ella misma a los 16 años en sus diarios, persiguiendo ser la chica que quería ser Dios. Podemos considerar las proezas académicas y la gran acumulación de premios en el colegio y la universidad como una manera de resaltar, de ser más que los demás. Trabajó siempre incansablemente, involucrándose en la mayor cantidad posible de tareas y sobresaliendo en todas ellas, hasta con su intento de suicidio, que lo utilizó posteriormente, para alardear con un aire de misterio frente a sus compañeras. Esa es, juntamente, la sobrecarga de un programa sin vacío y sin respiro, que después fue colmado con el trabajo en la casa, en la huerta, como escritora y en el pueblo, como publicista de su esposo y madre ideal de dos niños pequeños. 
Con respecto a su suicidio, este parece la elaboración de un ritual. Protege puertas y ventanas con cinta y toallas mojadas, deja el desayuno listo al lado de la cama de los niños y la ventana abierta para que no se ahoguen con el gas (aunque fuera uno de los inviernos más fríos que ha habido en Inglaterra), deja al lado del horno una nota con el teléfono de su psiquiatra - no deja explicación alguna- y sobre una toalla recuesta su cabeza dentro del horno con el gas abierto. El proceso da cuenta de una seria planificación. Como todo en su vida, no le gustaba lo espontáneo. No contaba con que el vecino se envenenara por el gas, se desmayara y no atendiera la puerta de calle, ni que la enfermera que cuidaba a los niños llegara más tarde de lo planeado. El horno tiene la connotación de ser el útero (Propp, 1983), por lo tanto su suicidio llevaría de alguna manera a cabo su deseo de regresar a la matriz; a la inmovilidad, a eludir la responsabilidad.

Debido a que el suicidio, en sí mismo, es un acto incomprensible y hasta ha sido penalizado, es interesante abordar el de una mujer que en apariencia lo tenía todo: una carrera sobresaliente, talento, belleza, una familia floreciente y juventud -murió a los 32 años. El sujeto suicida puede sentirse amenazado por instancias internas a las cuales necesita dar forma. Sin embargo, dichas instancias pueden no lograr ser puestas en palabras debido a un vacío en la cadena significante. Este vacío se produce en la represión. Al retornar lo reprimido en un intento de restituirlo y organizarlo, es posible que el sujeto busque una forma de metaforización en los actos. Así, el suicidio de Sylvia Plath, como un acting out, sería la expresión de un ritual organizado hacia el sostenimiento de esa palabra que ya no pudo ser metaforizada en la escritura, debido a que los fármacos bajaron las barricadas obsesivas, cediendo ante una invasión pulsional insostenible, en un estado de fragilidad psíquica que dio paso a la desimbolización de la perfección en la Muerte, en un ensayo suicida que, debido a una serie desastrosa de casualidades, tuvo como resultado el deceso de Plath, y casi el de su vecino, por envenenamiento mediante gas, como víctimas del holocausto. Esta relación entre una actuada cámara de gas y la muerte de los judíos se entendería a través de su poema Daddy, al igual que en su poema Edge, los últimos que escribiera Plath, en un ensayo fallido de dar sentido a un amenazante derrumbamiento yoico. 
La mujer se ha perfeccionado.

Su cuerpo

Muerto luce la sonrisa del acabamiento, La ilusión de un anhelo griego

Fluye por las volutas de su toga, Sus pies

Descalzos parecen decir: Hasta aquí hemos llegado, se acabó.

\section{Conclusión}

A lo largo de su vida, Sylvia Plath se debatió entre la búsqueda de la perfección y la frustración lacerante de no alcanzar sus imposibles ideales, lo que le generaba largos y profundos estados de depresión que, finalmente, le condujeron hacia el abismo de la desesperanza. Fue considerada por su maestro y reconocido poeta Robert Lowell como una hipnótica heroína trágica, una genio y una mujer de extremos que escribe mejor cuando está sumergida en ellos (Wisker, 2001: 64). Reconocemos en Plath a una artista en búsqueda de una constante superación personal, de una identidad y una palabra únicas e innovadoras, por tanto, una expresión de neurosis obsesiva. Por momentos aparece como una víctima de los efectos de su propio e imposible deseo: ser perfecta. En este sentido se observan en su historia personal severas depresiones que pueden confundirse con melancolizaciones y estados de producción frenética, casi febriles, que apuntan a desviar la mirada del analista hacia síntomas maníacos.

$7 \quad$ Aquí están los cuatro primeros versos de este poema. 
Existe una similitud entre el sujeto melancólico y el neurótico obsesivo en su posicionamiento frente al deseo del Otro, en tanto comparten la ambivalencia. Por eso, en relación al goce, se puede confundir la sintomatología melancólica autopunitiva con la relación a la muerte del neurótico obsesivo, en cuanto un retorno de lo sádico sobre sí mismo, y porque se propone como un sujeto pasivo frente a esa agresividad que intenta reprimir. Esto le llevaría a tener una relación del tipo masoquista con su Superyó que le conmina a gozar, es decir, a sentir placer a través del sufrimiento. Esta relación se hace tangible tanto en la vida como en la obra de Plath, por ejemplo, en su deseo imposible de ser perfecta y como el no serlo la hiere; o en su poesía más tardía, cuando se manifiestan imágenes de sacrificio; o como víctima del holocausto. Sin embargo, es su poesía previa la que la llevará a la fama donde se evidencian con mayor claridad el dominio técnico y los artificios defensivos en su estilo, más que en los contenidos de su escritura, que finalmente dan cuenta de su estructura psíquica como una neurosis obsesiva.

Como poeta de gran talento es importante recabar en Plath como creadora. El acto creador va más allá de las experiencias concretas de la vida. La génesis de una obra también está profundamente enraizada en las fantasías conscientes e inconscientes del creador. Es interesante recalcar que las fantasías que operan en la vida de la autora posiblemente sean las mismas que operan en su obra, pero también es cierto que es posible que un aspecto marginal de su vida pueda constituir su obra desde esta región de su vida psíquica. Es decir, su obra pone en escena su existencia más allá de su vida cotidiana, en un acto creador, como plantea Anzieu: "no deben confundirse el contenido manifiesto con la génesis, el producto con el proceso de producción" y, por lo tanto, tomar el poema como una profecía. ¿Hasta qué punto se puede considerar la creación poética una suerte de performadora de la realidad del autor?

Hay que recordar que Plath experimentó durante su infancia y adolescencia, no solamente la amenaza de sus pulsiones sexuales, que la sociedad duramente inhibía en las mujeres jóvenes, sino también una serie de sucesivas y dolorosas pérdidas, además de la situación social producida por la Segunda Guerra Mundial, lo cual plantea la posibilidad de que la restauración de un pseudo-equilibrio psíquico haya sido la escritura, frente a una desgarradura interna cara a cara con una realidad externa que amenazaba con la desintegración. 
Sin embargo, su búsqueda de la perfección y la necesidad de reconocimiento hicieron que la escritura como cuarto nudo, no haya podido dar el sostén que requería su psiquismo fragilizado.

\section{Bibliografía}

\section{Textos}

Abraham, Karl. Psicoanálisis Clínico, Buenos Aires: Ediciones Hormé S.A.E., 1994.

Anzieu, Didier et al. Psicoanálisis y Lenguaje, del cuerpo a la palabra, Buenos Aires: Editorial Kapelusz, 1981.

Cadoux, Bernard. Écritures de la psychose, Paris: Aubier, 1999.

Chemama, Roland. Diccionario de psicoanálisis, Buenos Aires: Amorrortu Ed., 1998.

Diyanni, Robert. Modern American Poets, Their Voices and Visions, New York: Random House Inc., 1987.

Freud, Sigmund. Inhibición, sintoma y angustia, Tomo XX, Buenos Aires: Amorrortu Ed. Obras Completas, 1992.

Freud, Sigmund. Más allá del principio de placer, Buenos Aires: Amorrortu Ed. Obras Completas, 1992.

Freud, Sigmund. El yo y el ello, Tomo XIX, Buenos Aires: Amorrortu Ed. Obras Completas, 1992.

Julien, Philippe. Psychose, Perversion, Névrose, la lecture de Jaques Lacan, Paris: Editions Érès, 2000.

Kirk, Connie Ann. Sylvia Plath, a biography, Westport: Greenwood Press, 2004.

Mannoni, Octave. La otra escena, Claves de lo imaginario, Buenos Aires: Amorrortu, 1997.

Plath, Sylvia. Árboles en Invierno; Madrid: Ediciones Hiperión, S.L., Segunda Edición, 2006. 
Plath, Sylvia. Poesía Completa, Tercera Edición, Madrid: Bartleby Editores, S. L. 2009.

Plath, Sylvia. The unabridged journals of Sylvia Plath, New York: Anchor Books, 2000.

Propp, Vladimir. Edipo a La Luz del Folklore y otros ensayos de etnografia, Barcelona: Ed. Bruguera, 1983.

Wagner-Martin, Linda. Sylvia Plath, Circe Ed. S.A.; Barcelona, 1997.

Wisker, Gina. Sylvia Plath, A beginner's guide, Londres: Hodder \&Stoughton, 2005.

\section{Referencias electrónicas}

Blake, Fred. Plathetic Fallacies, en la página web: 〈http://www.dgdclynx.plus. com/lynx56.html.

Bustamante, Cecilia. La desintegración de la vida; en la web en: 〈http://www. poeticas.com.ar/directorio/Poetas_miembros/Sylvia_Plath.html〉.

Galarza, Javier. De la poesía como sintoma y el lugar vacante de Dios, en su blog: 〈http://javiergalarzants.blogspot.com〉.

Gerbig, Andrea. Trapped in language: aspects of ambiguity and intertextuality in selected poetry and prose by Sylvia Plath, en la página web: 〈http:// findarticles.com/p/articles/mi_m2342/is_1_36/ai_89985877 >. 2009.

Hughes, Ted. On Sylvia Plath, «http://www.sylviaplath.de/plath/hughesonsylvia. html .

Lander, Rómulo. Ética y estética del acto suicida, publicado en la web en: 〈http://www.herreros.com.ar/melanco/lander.htm〉.

Orr, Peter. The Poet Speaks - Interviews with Contemporary Poets, Peter Orr entrevista a Sylvia Plath, en la web en: 〈http://www.sylviaplath.de/plath/ orrinterview.html >. 2009.

Uroff, Margaret Dixie. Sylvia Plath and Confessional Poetry: A Reconsideration, en la web en: 〈http://www.sylviaplath.de/plath/uroff.html〉.

Envío 9 de marzo/2011- Aceptación 29 de marzo/2011 